\title{
FAKTOR YANG BERHUBUNGAN DENGAN BROMAGE SCORE PADA PASIEN SPINAL ANASTESI DI RUANG PEMULIHAN
}

\author{
Wayan Eka Fitria*, Siti Fatonah*, Purwati* \\ *Jurusan Keperawatan Poltekkes Tanjungkarang
}

\begin{abstract}
Bromage score satu indikator respon motorik pasca spinal anastesi. spinal anastesi adalah metode anestesi dengan cara menyuntikkan obat analgetik lokal kedalam ruang subarachnoid di daerah lumbal. Penilaian status fisik (ASA) didapat rata-rata waktu pencapaian skala Bromage 2 pada pasien ASA I adalah 184,75 menit dan responden pasien ASA II 207 menit. Di salah satu rumah sakit di Bandar Lampung pasien pasca operasi dengan spinal anastesi respon motorik terbesar adalah $<4$ jam $(62,5)$ responden. Rancangan penelitian survey analitik dengan pendekatan cross sectional. Teknik pengambian sampel menggunakan teknik accidental sampling. Populasi adalah pasien pasca spinal anastesi di ruang pemulihan sebuah rumah sakit di Bandar Lampung dengan jumlah sampel 33 responden. Pengumpulan data menggunakan lembar observasi dengan menggunakan uji Chi Square. Hasil penelitian didapatkan adanya dua faktor yang berhubungan dengan bromage score yaitu status fisik ASA dengan nilai $\rho$ value $=0,000$ sedangkan nilai $\mathrm{OR}=105,00$ (9,932 - 1110.017) dan Umur dengan nilai $\rho$ value $=0,001$ sedangkan nilai $\mathrm{OR}=14.000$ (2,539 -77,208). Sedangkan yang tidak berhubungan yaitu faktor posisi pembedahan dengan nilai $\rho$ value $=0,665$. Peneliti berharap agar fakto-faktor yang dapat mempengaruhi bromage score pasien spinal anastesi tetap diperhatikan agar tidak terjadi komplikasi pasien pasca spinal anastesi.
\end{abstract}

Kata kunci: bromage score, spinal anastesi, , status fisik ASA, umur, waktu pulih

\section{LATAR BELAKANG}

Dalam setiap pembedahan diperlukan upaya untuk menghilangkan nyeri dengan memberikan anastesi. Istilah anastesi umum dipakai jika pemberian anestetik sistemik menghilangkan rasa nyeri (The loss off felling) disertai hilangnya kesadaran. Istilah analgesia merujuk pada hilangnya nyeri yang tidak disertai hilangnya kesadaran. Proses menghilangkan nyeri di suatu lokasi yang terbatas atau disalah satu bagian tubuh saja tanpa menghilangkan kesadaran (Sjamsuhidajat, 2010).

Anastesi spinal merupak tipe blok kondusif saraf yang luas dengan memasukan anastesia lokal kedalam ruang subarakhnoid di tingkat lumbal (biasanya L4 dan L5). Cara ini menghasilkan anastesia pada ekstremitas bawah, perineum dan abdomen bawah. Untuk prosedur fungsi lumbal, pasien dibaringkan miring dalam posisi lutut dada. Segera setelah penyuntikan, pasien dibaringkan terlentang. Jika diinginkan tingkat blok yang secara relatif tinggi, maka kepala dan bahu pasien diletakkan lebih rendah.
Pasien dalam pengaruh anastesi spinal atau lokal masih bangun dan sadar tentang sekelilingnya (Smeltzer, 2001).

Ada beberapa resiko yang mungkin timbul akibat anastesi, terutama pada pasien anastesi spinal, karena kadar anastesi dalam medula spinalis akan bergerak ke atas dan dapat mempengaruhi pernapasan, serta blok anastesi pada saraf vasomotorik simpatis dan serat saraf nyeri dan motorik menimbulkan vasodilatasi yang luas sehingga klien dapat mengalami penurunan tekanan darah yang secara tibatiba (Potter\&Perry, 2002).

Lamanya waktu yang dihabiskan pasien di ruang pemulihan tergantung pada berbagai faktor termasuk durasi dan jenis pembedahan, teknik anastesi, dan timbulnya komplikasi. Sebagian besar unit memiliki kebijakan yang menentukan dan memenuhi kriteria pengeluaran (Gwinnutt, 2011).

Kriteria penilaian yang digunakan untuk menentukan kesiapan pasien spinal anastesi dikeluarkan dari ruang anastesi care unit adalah bromage score. Bromage score merupakan salah satu indikator respon motorik pasca anastesi. Dengan 
penilaian Gerakan penuh dari tungkai score 0, Tidak mampu ekstensi tungkai score 1, Tidak mampu fleksi lutut score 2, Tidak mampu fleksi pergelangan kaki score 3. Jika nilai bromage score pasien telah mencapai 2 maka pasien dinyatakan pulih dari anastesi (Finucane, 2007).

Menurut Triyono (2015) dalam penelitinnya tentang hubungan status fisik ASA dengan waktu pencapaian bromage score 2 pada pada pasien spinal anastesi di ruang pemulihan RSUD Kanjurahan Kepanjen Kabupaten Malang terhadap penilaian status fisik (ASA) pra anestesi sangat penting dilakukan untuk mencegah faktor resiko komplikasi yang dapat mengancam jiwa pasien. Didapat rata-rata waktu pencapaian skala Bromage 2 pada pasien ASA I adalah 184,75 menit dan responden pasien ASA II 207 menit.

Menurut Harvina (2013) dalam penelitiannya tentang rerata waktu pasien pasca operasi tinggal di ruang pemulihan RSUP Dr Kariadi Semarang pada bulan Maret - Mei 2013. Klasifikasi status fisik pasien berdasarkan ASA merupakan predictor hasil dari suatu operasi. Didapatkan rerata waktu pasien tinggal di ruang pemulihan menurut kriteria klasifikasi status ASA pasien yang lebih lama yaitu status ASA II dengan waktu 55,00 menit sedangkan ASA I 53,93 menit.

Penelitian Nuriyadi (2012), menunjukkan bahwa pasien pasca sectio caesarea dengan spinal anestesi dosis bupivacain $\quad 0,5 \% \quad 20 \quad \mathrm{mg}$ memerlukan waktu pencapaian Bromage Score 2 pada menit ke 190-235, sedangkan pada bupivacain $0,5 \% \quad 15 \mathrm{mg}$ tercapai pada menit ke 155-195. Terdapat perbedaan lama waktu pencapaian Bromage Score 2 dengan beda waktu \pm 35 menit (lebih cepat pada dosis $15 \mathrm{mg}$ ). Penelitian Subiyantoro (2014), menunjukkan bahwa tidak terdapat pengaruh indeks masa tubuh (IMT) dengan waktu pencapaian Bromage Score 2 pada responden spinal anestesi.

Berdasarkan data ruang Pemulihan Bedah Sentral sebuah rumah sakit di Bandar Lampung. Berdasarkan hasil pre survey pada tanggal 5 Februari 2018 jumlah rata-rata pasien menggunakan spinal anastesi dari periode November April yaitu 342 orang pasien dengan Pasca anastesi spinal sebelum di pulangkan keruangan pasien dinilai terlebih dahulu bromage score. Pasien boleh dipulangkan keruangan apabila bromage score mencapai $\leq 2$. Didapatkan rata-rata pasien dipindahkan keruang perawatan dalam waktu $<4$ jam dan $\geq 4$ jam.

\section{METODE}

Rancangan penelitian ini adalah survei analitik dengan pendekatan cross sectional. Populasi dari penelitian ini adalah pasien pasca spinal anastesi di ruang pemulihan sebuahg rumah sakit di Bandar Lampung. Jumlah sampel pada penelitian ini adalah 33 responden. Instrumen pengumpulan data dalam penelitian ini menggunakan lembar observasi bromag score dan lembar ceklist untuk mengumpulkan data responden berupa usia, jenis kelamin, status fisik ASA, dan posisi pembedahan. Selanjutnya data akan dianalisi menggunakan uji $C h i$ Square.

\section{HASIL}

Tabel 1: Distribusi Frekuensi Status Fisik ASA (American Society of Anasthesiologi)

\begin{tabular}{lcc}
\hline Status Fisik ASA & f & $\%$ \\
\hline $\begin{array}{l}\text { Penderita Penyakit } \\
\text { Sistemik Ringan (ASA 2) }\end{array}$ & 22 & 55 \\
\hline $\begin{array}{l}\text { Penderita Penyakit } \\
\text { Sistemik Berat (ASA 3) }\end{array}$ & 18 & 45 \\
\hline Jumlah & 40 & 100 \\
\hline
\end{tabular}

Berdasarkan tabel di atas diketahui bahwa jumlah responden terbanyak adalah responden ASA 2 yaitu 22 responden (55\%), Sedangkan untuk ASA 318 responden $(45 \%)$. 
Tabel 2: Distribusi Frekuensi Faktor Umur

\begin{tabular}{lcc}
\hline \multicolumn{1}{c}{ Umur } & f & $\%$ \\
\hline Dewasa (18-45) & 17 & 42,5 \\
\hline Lansia (> 45 tahun) & 23 & 57,5 \\
\hline Jumlah & 40 & 100 \\
\hline
\end{tabular}

Berdasarkan tabel 2 diketahui bahwa jumlah responden terbanyak adalah responden dengan umur $>45$ tahun yaitu 23 responden $(57,5 \%)$, sedangkan 18-45 tahun sebanyak 17 responden $(42,5 \%)$.

Tabel 3: Distribusi Frekuensi Faktor Posisi Pembedahan

\begin{tabular}{lcc}
\hline \multicolumn{1}{c}{ Posisi pembedahan } & f & $\%$ \\
\hline Supinasi & 29 & 72,5 \\
\hline Litotomi & 11 & 27,5 \\
\hline Jumlah & 40 & 100 \\
\hline
\end{tabular}

Berdasarkan tabel di atas diketahui jumlah responden dengan posisis pembedahan supinasi 29 responden $(72,5 \%)$, sedangkan posisi pembedahan dengan litotomi 11 responden $(27,5 \%)$.

Tabel 4: Distribusi Frekuensi Lama Waktu Pencapaian Bromage Score

\begin{tabular}{lcc}
\hline $\begin{array}{c}\text { Waktu pencapaian } \\
\text { Bromage score }\end{array}$ & $\mathrm{f}$ & $\%$ \\
\hline < 4 Jam & 23 & 57,5 \\
\hline$\geq$ 4 Jam & 17 & 42,5 \\
\hline Jumlah & 40 & 100,0 \\
\hline
\end{tabular}

Berdasarkan tabel di atas diketahui bahwa jumlah responden paling banyak adalah waktu pencapaian Bromage score < 4 jam yaitu sebanyak 23 responden (62,5\%). Sedangkan untuk waktu pencapaian Bromage sore $\geq 4$ jam sebanyak 17 responden $(42,5 \%)$.

Tabel 5: Distribusi Frekuensi Faktor Jenis Kelamin

\begin{tabular}{lcc}
\hline \multicolumn{1}{c}{ Jenis Kelamin } & $\mathrm{f}$ & $\%$ \\
\hline Laki-laki & 24 & 60,0 \\
\hline Perempuan & 16 & 40,0 \\
\hline Jumlah & 40 & 100 \\
\hline
\end{tabular}

Berdasarkan tabel di atas diketahui jumlah responden laki-laki sebanyak 24 responden $(60 \%)$, sedangkan perempuan sebanyak 16 responden $(40 \%)$.

Tabel 6: Hasil Analisis Hubungan Status Fisik ASA dengan Waktu Pencapaian Bromage Score

\begin{tabular}{|c|c|c|c|c|}
\hline \multirow{3}{*}{ Status Fisik ASA } & \multicolumn{4}{|c|}{$\begin{array}{c}\text { Waktu Pencapaian } \\
\text { Bromage score }\end{array}$} \\
\hline & \multicolumn{2}{|c|}{$<4$ Jam } & \multicolumn{2}{|c|}{$\geq 4$ Jam } \\
\hline & $\mathrm{f}$ & $\%$ & $\mathrm{f}$ & $\%$ \\
\hline ASA 2 & 20 & 90,9 & 2 & 9,1 \\
\hline ASA 3 & 4 & 22,2 & 14 & 77,8 \\
\hline OR 95\% CI & \multicolumn{4}{|c|}{35,000} \\
\hline$\rho$ Value & \multicolumn{4}{|c|}{0,000} \\
\hline
\end{tabular}

Berdasarkan tabel di atas menunjukkan bahwa hubungan analisis antara status fisik ASA dengan waktu pencapaian bromage score di peroleh bahwa ada sebanyak 20 dari $22(90,9 \%)$ status fisik ASA 2 dengan waktu pencapaian bromage score $<4$ jam. Sedangkan diantara ASA 3 ada 4 dari 18 $(22,2 \%)$ yang mencapai waktu pencapaian bromage score $<4$ jam. Hasil uji statistik diperoleh nilai $\rho$ Value $=0,000$ maka dapat disimpulkan ada perbedaan proporsi kejadian antara status fisik ASA dengan waktu pencapaian bromage score (ada hubungan yang signifikan antara status fisik ASA dengan waktu pencapaian bromage score). Dari hasil analisis diperoleh pula nilai $\mathrm{OR}=35,000$ artinya status Fisik ASA 2 mempunyai peluang 35 kali waktu pencapaian bromage score $<4$ jam dibandingkan status fisik ASA 3.

Tabel 7: Hasil Analisis Hubungan Umur dengan Waktu Pencapaian Bromage Score

\begin{tabular}{|c|c|c|c|c|}
\hline \multirow{3}{*}{ Umur } & \multicolumn{4}{|c|}{$\begin{array}{c}\text { Waktu pencapaian } \\
\text { Bromage score }\end{array}$} \\
\hline & \multicolumn{2}{|c|}{$<4$ Jam } & \multicolumn{2}{|c|}{$\geq 4 \mathrm{Jam}$} \\
\hline & $\mathrm{f}$ & $\%$ & $\mathrm{f}$ & $\%$ \\
\hline Dewasa (18-45tahun) & 15 & 88,2 & 2 & 11,8 \\
\hline Lansia (18-45 tahun) & 9 & 39,1 & 14 & 60,9 \\
\hline$\overline{\text { OR } 95 \% \mathrm{CI}}$ & 11,667 & & & \\
\hline$\rho$ Value & 0,002 & & & \\
\hline
\end{tabular}


Berdasarkan tabel di atas Menunjukkan bahwa Hubungan analisis hubungan antara umur dengan waktu pencapaian bromage score di peroleh bahwa ada sebanyak 15 dari $17(88,2 \%)$ umur dewasa (18-45tahun) dengan waktu pencapaian bromage score $<4$ jam. Sedangkan diantara lansia ada 9 dari 23 $(39,1 \%)$ yang mencapai waktu pencapaian bromage score < 4 jam. Hasil uji statistik diperoleh nilai $\rho$ Value $=0,002$ maka dapat disimpulkan ada perbedaan proporsi kejadian antara umur dengan waktu pencapaian bromage score (ada hubungan yang signifikan antara umur dengan waktu pencapaian bromage score). Dari hasil analisis diperoleh pula nilai $\mathrm{OR}=11,667$ artinya umur dewasa (18-45 tahun) mempunyai peluang 11,667 kali waktu pencapaian bromage score $<4$ jam dibandingkan umur lansia ( $>45$ tahun).

Tabel 8: Hasil Analisis Hubungan Posisi Pembedahan dengan Waktu Pencapaian Bromage Score

\begin{tabular}{lcccc}
\hline & \multicolumn{4}{c}{ Waktu pencapaian } \\
& Umur & \multicolumn{4}{c}{ B Jamage } & score \\
\cline { 2 - 5 } & $\mathrm{F}$ & $\%$ & $\mathrm{f}$ & $\%$ \\
\hline Supinasi & 19 & 65,5 & 10 & 34,5 \\
\hline Litotomi & 5 & 45,5 & 6 & 54,5 \\
\hline OR 95\% CI & 2,280 & & & \\
\hline$\rho$ Value & 0,247 & & & \\
\hline
\end{tabular}

Berdasarkan tabel di atas Menunjukkan bahwa Hubungan analisis hubungan antara posisi pembedahan dengan waktu pencapaian bromage score di peroleh bahwa ada sebanyak 19 dari 29 $(65,5 \%)$ posisi pembedahan supinasi dengan waktu pencapaian bromage score < 4 jam. Sedangkan diantara posisi pembedahan litotomi ada 5 dari 11 $(45,5 \%)$ yang mencapai waktu pencapaian bromage score $<4$ jam. Hasil uji statistik diperoleh nilai $\rho$ Value $=0,247$ maka dapat disimpulkan tidak ada perbedaan proporsi kejadian antara posisi pembedahan dengan waktu pencapaian bromage score (tidak ada hubungan yang signifikan antara posisi pembedahan dengan waktu pencapaian bromage score).
Dari hasil analisis diperoleh pula nilai OR $=2,280$ artinya posisi pembedaha supinasi mempunyai peluang 2,280 kali waktu pencapaian bromage score < 4 jam dibandingkan posisi pembedahan litotomi

\section{PEMBAHASAN}

\section{Hubungan Status Fisik ASA dengan Waktu Pencapaian Bromage Score}

Hasil penelitian menunjukkan bahwa ada hubungan antara status fisik ASA dengan waktu pencapaian bromage score.

Hal ini sejalan dengan penelitian yang dilakukan oleh Triyono, Titik Endarwati, \& Ana Ratnawati (2011). Sebanyak 45 responden dengan status ASA 1 sebanyak 23 orang $(51,1 \%)$. Waktu pencapaian Bromage Score 2 sebagian besar termasuk dalam kategori cepat yaitu sebanyak 25 orang $(55,6 \%)$. Rata-rata waktu pencapaian skala Bromage score pada pasien ASA 11 adalah 184,75 menit dan responden pasien ASA 2207 menit. Hasil uji chi square didapatkan nilai dengan signifikasi ( $p$ value) 0,012. Ada hubungan status fisik ASA dengan waktu pencapaian bromage score 2 pada pasien spinal anastesi di ruang pemulihan RSUD Kanjurahan Kepajen Kabupaten Malang.

Menurut peneliti dari hasil penelitian yang dilakukan di ruang pemulihan adanya hubungan antara status fisik ASA dengan bromage score. Responden yang diikutkan dengan status fisik ASA 3 akan lebih lama untuk mencapai bromage score daripada pasien yang status fisik ASA $2 \mathrm{Hal}$ ini berhubungan dengan penyakit sistemik yang dimiliki responden. Hal ini juga berkaitan dengan lama tindakan operasi, yakni akan membutuhkan perawatan yang lebih lama di ruang pemulihan. Dengan demikian diharapkan pasien di monitor dengan baik sehingga tidak terjadi komplikasi pasien pasca spinal anastesi

\section{Hubungan Umur dengan Waktu Pencapaian Bromage Score}

Hasil penelitian menunjukkan bahwa ada hubungan antara umur dengan waktu pencapaian bromage score. 
Pada usia lanjut akan terjadi peningkatan peningkatan sensitifitas terhadap obat-obatan anastesi. pada pasien pediatrik karena luas permukaan tubuh yang lebih luas, resiko kehilangan panas dan terjadi hipotermi akan lebih besar. Bila ini terjadi akan memperlambat metabolisme dan pulih sadar pasca anastesi akan tertunda. Dengan meningkatnya usia, kapasitas fisik klien untuk beradaptasi dengan stress pembedahan terhambat karena mundurnya beberapa fungsi tubuh tertentu.

Menurut peneliti dari hasil yang dilakukan di ruang pemulihan ada hubungan antara umur dengan waktu pencapaian bromage score. Responden yang diikuti dengan umur 18-45 tahun lebih cepat dalam mencapai waktu bromage score. Hal ini berkaitan dengan semakin tua usia semakin semakin turunya beberapa fungsi tubuh tertentu. Dengan demikian diharapkan diberikan pelayanan optimal sehingga pasien tidak mengalami keterkambatan dalam mencapai waktu bromage score.

\section{Hubungan Posisi Pembedahan dengan Waktu Pencapaian Bromage Score}

Hasil penelitian menunjukkan bahwa tidak ada hubungan antara posisi pembedahan dengan waktu pencapaian bromage score.

Hal ini ditujukan dari teori Posisi pasien dimeja operasi bergantung pada prosedur pembedahan operasi yang akan dilakukan juga kondisi fisik pasien. Posisi tidak boleh menganggu struktur neuromuskular. Kenyamanan dan keselamatan klien harus diperhatikan.

Menurut peneliti dari hasil penelitian yang dilakukan di ruang pemulihan tidak adanya hubungan antara posisi pembedahan dengan bromage score. Responden yang diikutkan adalah posisi pembedahan dengan supinasi dan litotomi. Hal ini tidak berhubungan dengan waktu pencapaian bromage score karena pemilihan posisi pasien susuai dengan tindakan operasi

\section{KESIMPULAN}

Hasil penelitian menyimpulkan bahwa terdapat hubungan antara status fisik ASA dan umur dengan bromage score di ruang pemulihan, sebaliknya tidak ada hubungan antara posisi pembedahan dengan bromage score di ruang pemulihan.

Kesimpulan tersebut menyarankan kepada perawat agar tetap mempertahankan SOP pindah ruang pulih sadar serta memberikan informasi terkait durasi waktu mencapai gerak ekstremitas bawah kepada pasien di ruang pulih sadar.

\section{DAFTAR PUSTAKA}

Finucane. (2007). Complications of Regional Anesthesia.

Gwinnutt, C. L. (2014). Catatan Kuliah Anastesi klinis Edisi 3. Jakarta: EGC.

Harvina, Widya \& Akhmad. (2013). Rerata

Waktu Pasien Pasca Operasi Tinggal

DI ruang Pemulihan RSUP Dr

Kariadi Semarang Pada Bulan Maret

- Mei 2013. Porta Garuda.

Potter, \& Perry. (2002). Buku Ajar Keperawatan Konsep Proses dan Praktik. Jakarta: EGC.

Sjamsuhidajat ,R., \& De Jong W . (2010). Buku Ajar Ilmu Bedah (3 ed). Jakarta : EGC.

Triyono, Titik Endarwati, \& Ana Ratnawati. (2015). Hubungan Status Fisik (ASA) Dengan Waktu Pencapaian Bromage Score 2 Pada Pasien Spinal Anastesi DI Ruang Pemulihan RSUD Kanjuruhan Kepanjen Kabupaten Malang. eprints Poltekkes Jogja. 